\title{
Complete genome analysis of a rare human G3P[9] rotavirus posing as an AU-1 like strain
}

\author{
Apiradee Theamboonlers', Ornwalan Maiklang ${ }^{1}$, Thanunrat Thongmee1, Thaweesak Chieochansin', \\ Viboonsuk Vuthitanachot ${ }^{2}$ and Yong Poovorawan ${ }^{1 *}$
}

\begin{abstract}
Background: We performed phylogenetic and sequence analysis by Basic Local Alignment Search Tool (BLAST) of a complete Human Rotavirus (HRV) genome isolated from a hospitalized child with acute gastroenteritis in Thailand.

Findings: The results indicated an uncommon strain characterized by multiple re-assortments in the VP3, VP4, VP6, NSP1, NSP4 and NSP5 genes. The uncommon strain is genotype G3-P[9]-I3-R3-C3-M3-A3-N3-T3-E3-H6, which displays aspects of the AU-1, FRV-1 and corresponds to the feline/canine prototype G3P[9] strain.

Conclusions: The results suggested that nearly all the eleven gene segments of G3P[9] RVA strain CU365 might have originated from feline/canine RVAs (Rotavirus A).
\end{abstract}

Keywords: Human rotavirus (HRV); Uncommon strain; AU-1 like strain; G3P[9]

\section{Findings}

Rotavirus group A is the most common cause of severe acute gastroenteritis among infants and young children with a mortality rate of 454,000-705,000 annually in children under 5 years of age especially in developing countries (Parashar et al. 2006). The predominant mode of transmission is by fecal-oral route and the dramatic spread occurs in winter. Rotavirus is a member of the Rotavirus genus, Reoviridae family and has a double stranded RNA genome. The viral capsid is triple-layered; the core layer contains the virus genome that is characterized by 11 segments encoding either structural viral proteins VP7, VP4, VP6, VP1, VP2 and VP3 or nonstructural NSP1, NSP2, NSP3, NSP4 and NSP5 genes which show the genotype constellation of Gx-P[x]-Ix-Rx-CxMx-Ax-Nx-Tx-Ex-Hx, respectively (Matthijnssens et al. 2011a). The outer capsid protein consists of VP7, glycoprotein or G-protein determines the type specificity of $\mathrm{G}$ and VP4, protease-cleaved or P- protein determined P types. The four common strains G1P [8], G3P [8], G4P [8] and G2P [4] of rotavirus predominate globally but the prevalence of strains can vary geographically and unusual strains also can occur. The G3 strains are the

\footnotetext{
* Correspondence: Yong.P@chula.ac.th

${ }^{1}$ Center of Excellence in Clinical Virology, Department of Pediatrics, Faculty of Medicine, Chulalongkorn University and Hospital, Bangkok 10330, Thailand Full list of author information is available at the end of the article
}

genotype with a broad host range and have been detected in several host species. Apart from its impact on human health, rotavirus also infects animals and is a pathogen of domestic animals. According to previous reports, uncommon rotavirus strains sharing genetic features of various virus strains have been isolated from humans and animals (Matthijnssens et al. 2011b). Direct interspecies transmission and exchange of dsRNA segments via re-assortment may account for the detection of animal rotavirus strains in humans or vice versa (Palombo 2002). The P[9] rotavirus strain's frequency amounts to less than $2.5 \%$ worldwide, while it is common in felines (Khamrin et al. 2007). Although the G3P [9] strain is rarely detected in humans it has been documented in Japan, Thailand and Spain (Khamrin et al. 2007; Iizuka et al. 1994; Sánchez-Fauquier et. al. 2006; Kaga et al. 1994).

The study was approved by the Ethics Committee, Faculty of Medicine, Chulalongkorn University, Thailand (IRB number 129/52). A 14-month-old boy was admitted to the district hospital, Chum Phae, Khon Kaen province, northeast Thailand in November 2008. He had a 2-day history of fever and watery diarrhea and was diagnosed with acute gastroenteritis. He received supportive treatment and intravenous fluid to compensate for dehydration. He was discharged after 2 days of admission with complete recovery. His stool (CU365) was sent 
to the Center of Excellence in Clinical Virology for etiological investigation, and it was found to be positive for rotavirus RNA by RT-PCR (reverse transcriptase polymerase chain reaction). Briefly, viral RNA was extracted by RBC Viral Nucleic Acid Extraction Kit ( RBC Bioscience, Taipei, Taiwan) following the manufacturer's instructions. RT-PCR of the complete genome was performed using specific primer sets (available on request) under conditions described previously (Theamboonlers et al. 2005). To purify the PCR products, the HiYield Gel/PCR DNA fragments extraction Kit (RBC Bioscience, Taipei, Taiwan) was used according to the manufacturer's instructions. Complete genome sequencing using specific primers was performed by First BASE Laboratories Shd Bhd (Salangor Darul Ehsan Malaysia). For sequence analysis, BLAST analysis was performed subsequently. (http://blast.ncbi.nlm. nih.gov/Blast.cgi, http://rotac.regatools.be/). The strain sequences were submitted to the GenBank database under accession numbers: JN706577 for NSP1 gene, JN706599 for NSP2 gene, JN706621 for NSP3 gene, JN 706643 for NSP4 gene, JN706665 for NSP5 gene, JN 706445 for VP1 gene, JN706480 for VP2 gene, JN706511 for VP4 gene, JN706508 for VP3 gene, JN706533 for VP6 gene, JN706555 for VP7 gene of the studied strain.

Based on all eleven RNA segments, the uncommon strain (CU365) showed a genotype of G3-P[9]-I3-R3-C3-M3-A3N3-T3-E3-H6 which suggested a close relationship with L621 human rotavirus A strain RVA/Human-tc/CHN/ L621/2006/G3P[9] (Wang et al. 2013) in NSP2, NSP3, NSP4, VP2, VP6 genes with $99 \%$ nucleotide identity by BLAST analysis which might have originated from feline/canine RVA strains including AU-1 like strains and the prototype strain BA222 of genotype G3-P[9]I3-R3-C3-M3-A3-N3-T3-E3-H3 constellation (Matthijnssens et al. 2011a; Iizuka et al. 1994; Kaga et al. 1994). In addition, the nucleotide identity between CU 365 and rotavirus AU-1 which is related to bovine rotaviruses (Nakagomi and Kaga 1995) for the NSP1 gene amounted to $99 \%$ identity. Moreover, the nucleotide identity between CU365 and the RVA/Human-tc/THA/T152/1998/G12P [9] (Rahman et al. 2007) strain's VP1 gene was found to be $97 \%$. Interestingly, the percent nucleotide identity between our study strain and the canine strain was also demonstrated to be $96 \%$ in VP3 (Matthijnssens et al. 2011b). In addition, the nucleotide identity between the VP4 gene of CU365 and human rotavirus strain AU-1 (Isegawa et al. 1992) was shown to be $99 \%$. The nucleotide identity between the VP7 gene of CU365 and strain 0802 of the emerging G3 rotaviruses in Hong Kong detectable in a 3-year-old boy (Mitui et al. 2011) was found to be $99 \%$. The comparison between the observed genotype constellation for CU365 and other related known human and animal RVA genotype constellation is shown in Table 1. Multiple sequence alignments were compared using Clustal W v1.83 and phylogenetic trees were created with MEGA software v4.1 using the neighbor-joining method of measuring phylogenetic distances. A maximum likelihood tree derived from 1000 bootstraps was constructed to show the relationship between the recently re-assorted Thai HRV strain CU365 and other HRV strains obtained from GenBank (Figures 1 and 2).

Table 1 Complete genotype constellations of known completely sequenced, CU365, DS-1, Wa, AU-1-like, FRVs, CRVs and feline/canine-like HRV strains

\begin{tabular}{|c|c|c|c|c|c|c|c|c|c|c|c|c|}
\hline \multirow[t]{2}{*}{ Strain name } & \multirow[t]{2}{*}{ Genogroup } & \multicolumn{11}{|c|}{ Genomic constellation } \\
\hline & & VP7 & VP4 & VP6 & VP1 & VP2 & VP3 & NSP1 & NSP2 & NSP3 & NSP4 & NSP5 \\
\hline RVA/Human-tc/jpn/AU-1/1982/G3P3[9] & AU-1-like & G3 & $\mathrm{P}[9]$ & 13 & R3 & $\mathrm{C} 3$ & M3 & A3 & N3 & T3 & E3 & $\mathrm{H} 3$ \\
\hline RVA/Human-tc/CHN/L621/2006/G3P[9] & AU-1-like & G3 & $\mathrm{P}[9]$ & 13 & R3 & $\mathrm{C} 3$ & M3 & A3 & N3 & T3 & E3 & $\mathrm{H} 6$ \\
\hline RVA/Human-wt/CHN/E2451/2011/G3P[9] & AU-1-like & G3 & $\mathrm{P}[9]$ & 13 & R3 & $\mathrm{C} 3$ & M3 & A3 & N3 & T3 & E3 & H6 \\
\hline RVA/Human-tc/THA/CU-365/2008/G3P[9] & AU-1-like & G3 & $\mathrm{P}[9]$ & 13 & R3 & $\mathrm{C} 3$ & M3 & A3 & N3 & T3 & E3 & $\mathrm{H} 6$ \\
\hline RVA/Human-tc/THA/t152/1998/G12P[9] & AU-1-like & G3 & $\mathrm{P}[9]$ & 13 & R3 & $\mathrm{C} 3$ & M3 & $\mathrm{A} 12$ & N3 & T3 & E3 & H6 \\
\hline RVA/Human-tc/ITA/PA260-97/1997/G3P[3] & AU-1-like and Cat97-like & G3 & $P[3]$ & 13 & R3 & $\mathrm{C} 3$ & M3 & A15 & N2 & T3 & E3 & H6 \\
\hline RVA/Dog-tc/ISR/Ro1845/1985/G3P3 & Cat97-like & G3 & $P[3]$ & 13 & R3 & $\mathrm{C} 3$ & M3 & A9 & N2 & $\mathrm{T} 3$ & E3 & H6 \\
\hline RVA/Dog-tc/ITA/RV198-95/1995/G3P3 & Cat97-like & G3 & $P[3]$ & 13 & R3 & $\mathrm{C} 3$ & M3 & A9 & N2 & $\mathrm{T} 3$ & E3 & H6 \\
\hline RVA/Cat-tc/AUS/Cat2/1984/G3P[9] & Cat97-like and BA222-05-like & G3 & $\mathrm{P}[3]$ & 13 & R3 & $\mathrm{C} 3$ & M3 & A3 & N1 & T6 & E3 & $\mathrm{H} 3$ \\
\hline RVA/Cat-wt/ITA/BA222/2005/G3P[9] & BA222-05-like & G3 & $\mathrm{P}[9]$ & 12 & R2 & $\mathrm{C} 2$ & M2 & A3 & N1 & $\mathrm{T} 3$ & E2 & $\mathrm{H} 3$ \\
\hline RVA/Human-wt/ITA/PAH136/1996/G3P[9] & BA222-05-like & G3 & $\mathrm{P}[9]$ & 12 & R2 & $\mathrm{C} 2$ & M2 & A3 & N1 & T6 & E2 & $\mathrm{H} 3$ \\
\hline RVA/Human-wt/ITA/PA158/1996/G3P[9] & BA222-05-like & G3 & $\mathrm{P}[9]$ & 12 & $\mathrm{R} 2$ & $\mathrm{C} 2$ & M2 & A3 & N2 & T6 & E2 & $\mathrm{H} 3$ \\
\hline RVA/Human-DS-1 & DS-1 & $\mathrm{G} 2$ & $P[4]$ & 12 & $\mathrm{R} 2$ & $\mathrm{C} 2$ & M2 & A2 & N2 & $\mathrm{T} 2$ & E2 & $\mathrm{H} 2$ \\
\hline RVA/Human-Wa & Wa & G1 & $\mathrm{P}[8]$ & 11 & R1 & $\mathrm{C} 1$ & M1 & $\mathrm{A} 1$ & N1 & $\mathrm{T} 1$ & E1 & $\mathrm{H} 1$ \\
\hline
\end{tabular}

Strain in bold has been invesgated in this study. 

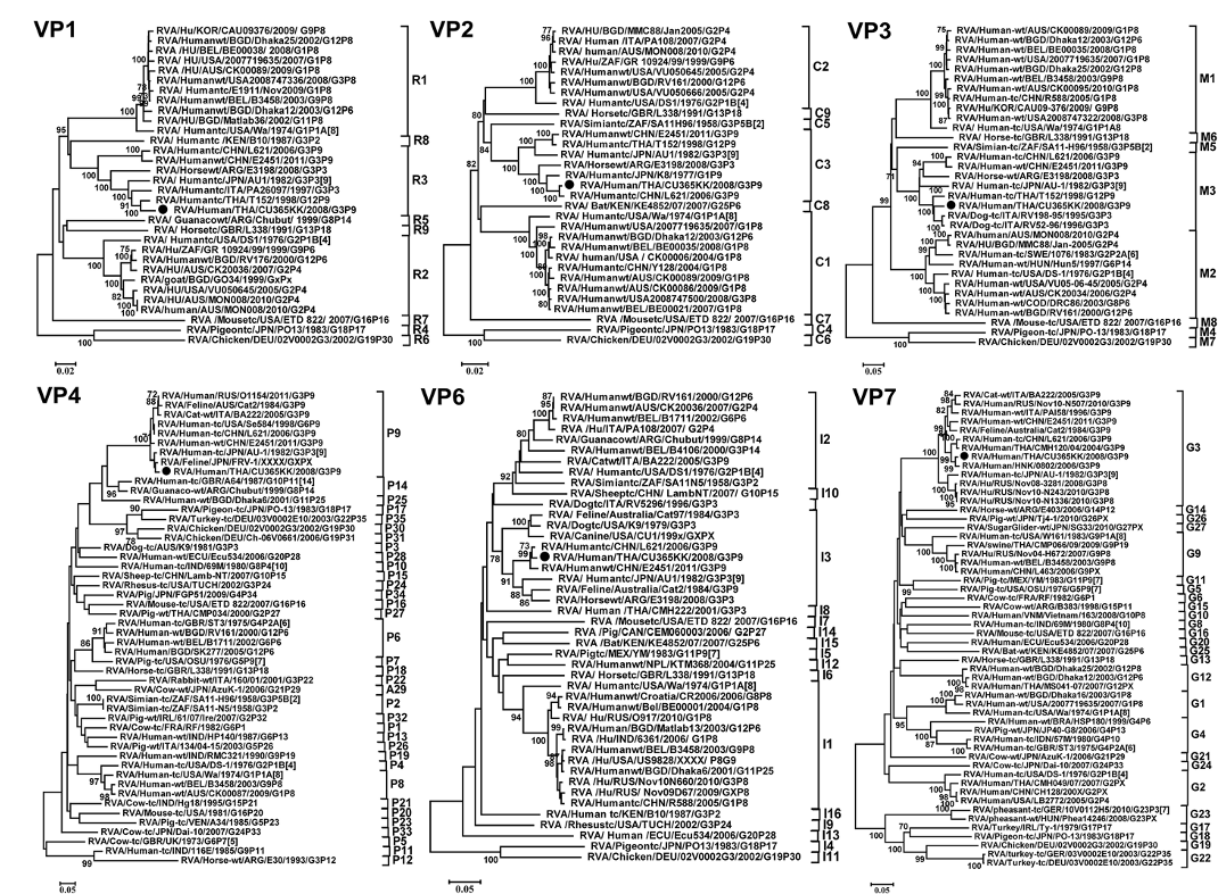

Figure 1 Phylogenetic trees constructed from the nucleotides sequences of VP1, VP2, VP3, VP4, VP6 and VP7 genes from this current study with reference strains from GenBank.

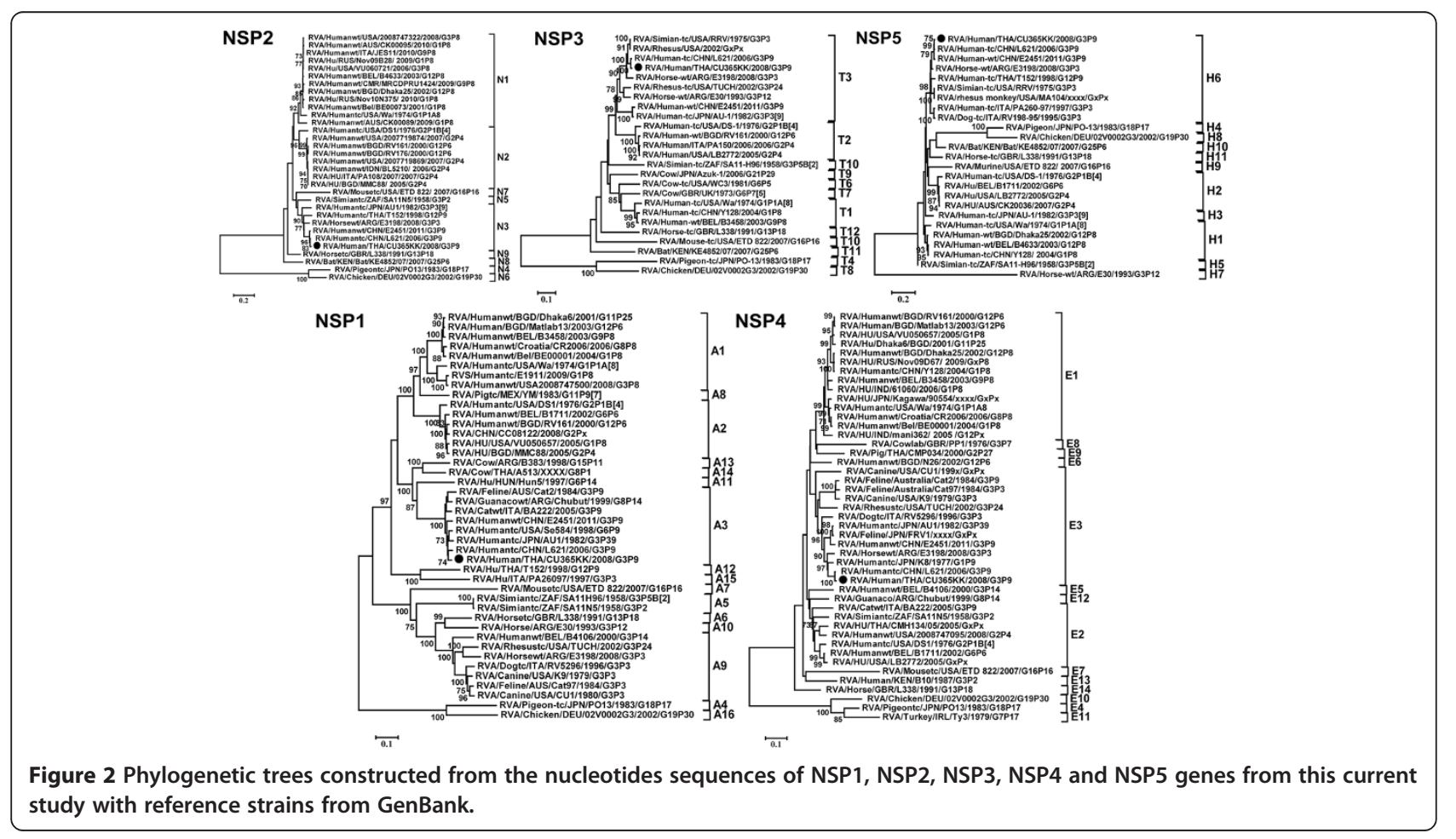


It has been found in previous studies that genotype G3 can be detected in several host species including humans, rabbits, monkeys, pigs, birds, cats, dogs, horses, mice, cows and lamb (Estes and Kapikian 2007; Martella et al. 2003). The P [9] genotype has also frequently been isolated from humans, cats and dogs and hence, has been named the feline/canine-like strain (Wang et al. 2013; Nakagomi et al. 1985; Mochizuki et al. 1997). A previous report on children afflicted with diarrhea in Japan showed that these children carried an AU-1-like and FRV-1-like G3P[9] rotavirus prototype strain (Iizuka et al. 1994; Kaga et al. 1994), which suggests an interspecies transmission event from cats/dogs to humans. The previously reported complete genome analysis investigated two rare G3P [9] rotavirus (PAH136/96 and PAI58/96) isolated from children with diarrhea which were recognized as assortments of genes closely related to rotaviruses from cats, ruminants and humans. The results suggested multiple transmissions of genes from animal to human strains of rotaviruses (De Grazia et al. 2010) identical to the previous study of complex evolutionary patterns of two rare human G3P[9] rotavirus strains also possessing a feline/canine-like H6 genotype on an AU-1-like genotype constellation (Wang et al. 2013). Other reports on similar reassortment include AU-1-like human G3P[9] strains detected in USA and Italy which also showed reassortments with canine and feline G3P[9] strains or other human strains. The fulllength genome sequence of a feline G3P[9] rotavirus (RV) strain, BA222, identified from the intestinal content of an adult cat, was determined. Strain BA222 possessed a G3-P[9]-I2-R2-C2-M2-A3-N1-T3-E2-H3 genomic constellation, differing substantially from other feline RVs (De Grazia et al. 2010; Grant et al. 2011; De Grazia et al. 2008; Martella et al. 2011). In addition, three G3P [9] rotaviruses, detected in children hospitalized with gastroenteritis in Palermo, Italy, were found to be genetically related to strains of either human or feline origin in the VP7, VP4, and VP6 genes. In contrast, in the NSP4 gene the viruses resembled G2P[4] human strains, suggesting a reassortment between AU-1-like and Kunlike strains (De Grazia et al. 2008). From these results suggested that future studies of cat and dog stool specimens would be of interest to survey the frequency of interspecies transmission, to monitor the co-evolution of human and animal rotavirus strains and to identify the human/animal reassorted viruses (Grant et al. 2011). Altogether, the findings suggest that feline RVs are genetically diverse and that human RVs may occasionally originate either directly or indirectly (via reassortment) from feline RVs (Martella et al. 2011). The new RV classification system, established by Matthijnssens et al. (Matthijnssens et al. 2011b) allows data to accumulate rapidly in order to elucidate the genetic relationships among human and animal RV strains. Overall, the findings of previous studies have demonstrated that gathering information on animal viruses is fundamental to better understand the evolution of human RVs, especially those that do not belong to the common Wa like and DS-1-like families (Martella et al. 2011).

In conclusion, we have described the recent RV reassortment of the VP1, VP2, VP4, VP6, VP7, NSP1, NSP2, NSP3, NSP4 and NSP5 genes in a strain isolated from a child in Thailand in 2008 with characteristics consistent with strain 621 from China-Wuhan which is the AU-1like and canine/feline-like RV strain. Interestingly, the VP3 gene in this study was closely related to the canine strain RV52-96. This is the first report on complete genome analysis of G3P[9] RVAs from Thailand, and our results indicate that feline/canine RVA can be transmitted to a human host. This finding highlights the risk of reassorted RV transmission between humans and animals. In addition, due to the apparently random nature of RVA re-assortment, it underscores the need for future studies on molecular characterization of whole genomes of RVAs in order to detect potentially important viral re-assortments.

\section{Consent}

Written informed consent was obtained from the patient's guardian/parent/next of kin for the publication of this report and any accompanying images.

\section{Competing interests}

The authors declare that they have no competing interests.

\section{Authors' contributions}

AT, OM, TT, TC, W, YP carried out the contributions to conception and design analysis and interpretation of data, molecular genetic studies, participated in the sequence alignment, drafted and final approval of the manuscript to be published. All authors read and approved the final manuscript.

\section{Acknowledgment}

The study was supported by a grant from The Higher Education Research Promotion and National Research University Project of Thailand Office of the Higher Education Commission (HR1155A), the Center of Excellence in Clinical Virology, Chulalongkorn University, CU Centenary Academic Development Project, Outstanding Professor of the Thailand Research Fund (DPG5480002) and King Chulalongkorn Memorial Hospital, National Research Council of Thailand, the Ratchadapheisek somphot Endowment Fund of Chulalongkon University (RES560530093), Integrated Innovation Academic Center IIAC Chulalongkorn University Centenary Academic Development Project (CU56HR01), Chumpare Hospital, Khon Kaen for providing the samples, We would like to thank Ms. Petra Hirsch and Mr. Brian Muchmore for reviewing the manuscript.

\section{Author details}

${ }^{1}$ Center of Excellence in Clinical Virology, Department of Pediatrics, Faculty of Medicine, Chulalongkorn University and Hospital, Bangkok 10330, Thailand.

${ }^{2}$ Chum Phae Hospital, Chum Phae, Khon Kaen, Thailand.

Received: 4 June 2013 Accepted: 22 October 2013

Published: 26 October 2013

\section{References}

De Grazia S, Giammanco GM, Martella V, Ramirez S, Colomba C, Cascio A, Arista S (2008) Rare AU-1-like G3P[9] human rotaviruses with a Kun-like NSP4 gene detected in children with diarrhea in Italy. J Clin Microbiol 46:357-360 
De Grazia S, Giammanco GM, Potgieter CA, Matthijnssens J, Banyai K, Platia MA, Colomba C, Martella V (2010) Unusual assortment of segments in 2 rare human rotavirus genomes. Emerg Infect Dis 16:859-862

Estes M, Kapikian A (2007) Rotaviruses. In: Knipe DM, Howley PM, Griffin DE, Lamb RA, Martin MA, Roizmzn B (eds) Fields Virology, 5th edn. Kluver Health/ Lippincott, Williams\&Wilkins, Philadelphia, pp 1917-1974

Grant L, Esona M, Gentsch J, Watt J, Reid R, Weatherholtz R, Santosham M, Parashar U, O'Brien K (2011) Detection of G3P[3] and G3P[9] rotavirus strains in American Indian children with evidence of gene reassortment between human and animal rotaviruses. J Med Virol 83:1288-1299

lizuka M, Chiba M, Masamune O, Kaga E, Nakagomi T, Nakagomi O (1994) A highly conserved genomic RNA constellation of Japanese isolates of human rotaviruses carrying $\mathrm{G}$ serotype 3 and $\mathrm{P}$ serotype 9 . Res Virol 145:21-24

Isegawa Y, Nakagomi O, Nakagomi T, Ueda S (1992) A VP4 sequence highly conserved in human rotavirus strain AU-1 and feline rotavirus strain FRV-1. J Gen Virol 73:1939-1946

Kaga E, lizuka M, Nakagomi T, Nakagomi O (1994) The distribution of G (VP7) and $P$ (VP4) serotypes among human rotaviruses recovered from Japanese children with diarrhea. Microbiol Immunol 38:317-320

Khamrin P, Maneekarn N, Peerakome S, Tonusin S, Phan TG, Okitsu S, Ushijima H (2007) Molecular characterization of rare G3P[9] rotavirus strains isolated from children hospitalized with acute gastroenteritis. J Med Virol 79:843-851

Martella V, Ciarlet M, Camarda A, Pratelli A, Tempesta M, Greco G, Cavalli A, Elia G, Decaro N, Terio V, Bozzo G, Camero M, Buonavoglia C (2003) Molecular characterization of the VP4, VP6, VP7, and NSP4 genes of lapine rotaviruses identified in italy: emergence of a novel VP4 genotype. Virol 314:358-370

Martella V, Potgieter AC, Lorusso E, De Grazia S, Giammanco GM, Matthijnssens J, Bányai K, Ciarlet M, Lavazza A, Decaro N, Buonavoglia C (2011) A feline rotavirus G3P[9] carries traces of multiple reassortment events and resembles rare human G3P[9] rotaviruses. J Gen Virol 92:1214-1221

Matthijnssens J, Ciarlet M, McDonald SM, Attoui H, Bányai K, Brister JR, Buesa J, Esona MD, Estes MK, Gentsch JR, Iturriza-Gómara M, Johne R, Kirkwood CD, Martella V, Mertens PP, Nakagomi O, Parreño V, Rahman M, Ruggeri FM, Saif LJ, Santos N, Steyer A, Taniguchi K, Patton JT, Desselberger U, Van Ranst M (2011a) Uniformity of rotavirus strain nomenclature proposed by the rotavirus classification working group (RCWG). Arch Virol 156:1397-1413

Matthijnssens J, De Grazia S, Piessens J, Heylen E, Zeller M, Giammanco GM, Bányai K, Buonavoglia C, Ciarlet M, Martella V, Van Ranst M (2011b) Multiple reassortment and interspecies transmission events contribute to the diversity of feline, canine and feline/canine-like human group A rotavirus strains. Infect Genet Evol 11:1396-1406

Mitui MT, Chan PK, Nelson EA, Leung TF, Nishizono A, Ahmed K (2011) Co-dominance of G1 and emerging G3 rotaviruses in Hong Kong: a threeyear surveillance in three major hospitals. J Clin Virol 50:325-333

Mochizuki M, Nakagomi T, Nakagomi O (1997) Isolation from diarrheal and asymptomatic kittens of three rotavirus strains that belong to the AU-1 genogroup of human rotaviruses. J Clin Microbiol 35:1272-1275

Nakagomi O, Kaga E (1995) Distinctness of NSP1 gene of human rotavirus AU-1 from NSP1 gene of other human genogroups. Res Virol 146:423-428

Nakagomi O, Nakagomi T, Oyamada H, Suto T (1985) Relative frequency of human rotavirus subgroups 1 and 2 in Japanese children with acute gastroenteritis. J Med Virol 17:29-34

Palombo EA (2002) Genetic analysis of group A rotaviruses: evidence for interspecies transmission of rotavirus genes. Virus Genes 24:11-20

Parashar UD, Gibson CJ, Bresee JS, Glass RI (2006) Rotavirus and severe childhood diarrhea. Emerg Infect Dis 12:304-306

Rahman M, Matthijnssens J, Yang X, Delbeke T, Arijs I, Taniguchi K, Iturriza-G ómara M, Iftekharuddin N, Azim T, Van Ranst MJ (2007) Evolutionary history and global spread of the emerging g12 human rotaviruses. Virol $81: 2382-2390$

Sánchez-Fauquier A, Montero V, Moreno S, Solé M, Colomina J, Iturriza-Gomara M, Revilla A, Wilhelmi I, Gray J; Gegavi/VIGESS-Net Group (2006) Human rotavirus $\mathrm{G} 9$ and $\mathrm{G} 3$ as major cause of diarrhea in hospitalized children Spain. Emerg Infect Dis 12:1536-1541
Theamboonlers A, Veravigrom M, Yambangyang $O$, Trairatvorakul $P$ Chongsrisawat $V$, Poovorawan $Y$ (2005) The incidence of rotavirus a isolates of $G$ genotype in Thailand in 2002-2004. Acta Virol 49:111-115

Wang YH, Pang BB, Zhou X, Ghosh S, Tang WF, Peng JS, Hu Q, Zhou DJ, Kobayashi N (2013) Complex evolutionary patterns of two rare human G3P[9] rotavirus strains possessing a feline/canine-like H6 genotype. J Gen Virol 73(Pt 8):1939-1946

doi:10.1186/2193-1801-2-569

Cite this article as: Theamboonlers et al:: Complete genome analysis of a rare human G3P[9] rotavirus posing as an AU-1 like strain. SpringerPlus 2013 2:569.

\section{Submit your manuscript to a SpringerOpen ${ }^{\circ}$ journal and benefit from:}

- Convenient online submission

Rigorous peer review

- Immediate publication on acceptance

- Open access: articles freely available online

- High visibility within the field

- Retaining the copyright to your article

Submit your next manuscript at $>$ springeropen.com 